\title{
REBECCA WEST E A ESCRITA FEMININA DA PRIMEIRA GUERRA EM THE RETURN OF THE SOLDIER
}

\begin{abstract}
Denise Borille ${ }^{1}$
Resumo: Este artigo tem como objetivos analisar a escrita feminina do trauma de guerra no romance The Return of The Soldier (1918), da autora inglesa Rebecca West, e verificar, mais especificamente, como homens e mulheres foram igualmente afetados pelo trauma da Primeira Guerra. O soldado Chris Baldry retorna do front afetado por uma amnésia traumática que o impede de recordar como era sua vida antes da guerra. De volta ao lar, ele reencontra três mulheres vivendo em sua casa: sua esposa, Kitty, a quem ele não reconhece; a sua ex-amante, Margaret, que ainda o ama; e, por último, sua prima, Jenny. Em termos simbólicos, é possível pensar que a casa onde as três mulheres vivem com Chris representa uma espécie de "laboratório"; um locus de onde elas observam a guerra e formulam seus pontos de vista a respeito desse conflito.

Palavras-chave: Primeira Guerra Mundial; Escrita feminina do trauma de guerra; Teoria do Trauma.

Abstract: It is the aim of this paper to analyze women writing of war trauma in Rebecca West's The Return of The Soldier (1918), and to address, more specifically, how both men and women suffered from the trauma inflicted by World War I. Chris Baldry is a soldier who returns from the war front struck by traumatic amnesia, which prevents him from remembering what his life was like before the war. Back home, he finds three women living in his house: his wife, Kitty, whom he does not recognize; Chris's ex-lover, Margaret, who still loves him; and, finally, his cousin, Jenny. In symbolic terms, it is possible to think that the house where the three women live in with Chris represents a kind of "laboratory", a locus from which they observe World War I and formulate their views on this conflict.
\end{abstract}

Keywords: World War I; Women Writing of War Trauma; Trauma Theory.

1 Professora na PUC-Minas. Foi bolsista da CAPES de doutorado-sanduíche na Kingston University London (2015).

E-mail: deniseborille1@gmail.com 
Rebecca West publicou The Return of the Soldier (O Retorno do Soldado - minha tradução) em 1918, no mesmo ano em que a Primeira Guerra chegou ao fim. Embora ela tenha descrito sua experiência na guerra como passiva, seu romance traz uma visão peculiar acerca do sentimento de angústia vivenciado por não-combatentes, mais notadamente, pelas mulheres. As consequências da guerra afetaram a sociedade como um todo, conforme elucida o historiador Eric Hobsbawm:

The monster of twentieth-century total war was not born full-sized. Nevertheless, from 1914 on, wars were unmistakably mass wars... Even in industrial societies so great a manpower mobilization puts enormous strains on the labour force, which is why modern mass wars both strengthened the powers of organized labour and produced a revolution in the employment of women outside the household: temporarily in the First World War, permanently in the Second World War. (HOBSBAWM, 1996, pp. 44-45).

A passagem não apenas reforça a ideia dos efeitos da guerra sobre as mulheres, que de bom grado ou não aderiram à força de trabalho, como também ressalta a inserção massiva das mulheres no mercado de trabalho a partir de 1914, juntamente com a Primeira Guerra. Além da premissa de mobilização de trabalho em massa de Hobsbawm, é possível pensar que o impacto psicológico dos traumas de guerra foi igualmente sentido por todos os envolvidos na guerra, homens, mulheres e crianças. A guerra afetou a vida de cidadãos civis e não civis de forma indistinta.

A ideia de uma tragédia que afetou a vida de todos está presente na primeira página do romance de Rebecca West. A narrativa começa com a descrição da história do filho morto e como a morte de Oliver afetou Chris (seu pai), Kitty (sua mãe) e Jenny (sua tia, a narradora), de formas semelhantes. Jenny descreve como ela e Kitty revisitavam constantemente o quarto do bebê, que permaneceu intacto por cinco anos após sua morte, bem como as memórias dolorosas causadas por esse hábito:

And along the mantelpiece, under the loved print of the snarling tiger, in attitudes that were at once angular and relaxed, as though they were ready for play at their master's pleasure, but found it hard to keep from drowsing in this warm weather, sat the Teddy Bear and the chimpanzee and the wooly white dog and the black cat with eyes that roll. Everything was there except Oliver. I turned away so that I might not spy on Kitty revisiting her dead. (WEST, 2004, p.4).

A descrição da decoração de animais no quarto do bebê sugere a imagem de uma floresta inanimada, cujos habitantes foram subitamente abandonados por seu guardião. A metáfora sugere que a família inteira caiu em um estado letárgico após a morte da criança, vivenciando a experiência traumática de abandono.

O episódio do filho morto é apresentado no primeiro e no último capítulos, evento esse que abre e encerra o enredo, o que sugere um paralelo entre o bebê morto e o regresso do pai soldado ferido à casa. A aparência de Chris Baldry é descrita como pálida e desgas- 
tada, sendo que seu estado mental é afetado por delírios e profunda introspecção, causados pela guerra. De certa forma, ele se assemelha a um fantasma. O trauma vivenciado por Chris, sob a forma de distúrbio de estresse pós-traumático, deixa-o em um estado constante de suspensão, em uma espécie de limbo. Ele aparenta estar "possuído" e isso causa estranhamento para as mulheres da casa. Tal reação aparece recorrentemente em casos de distúrbio de estresse pós-traumático e, de acordo com Cathy Caruth, isso acontece porque "(...) the event is not assimilated or experienced fully at the time, but only belatedly, in its repeated possession of the one who experiences it. To be traumatized is precisely to be possessed by an image or event." (CARUTH, 1995, p. iv-v).

A mente de Chris o impele constantemente a voltar para as cenas de batalha traumáticas vividas durante a guerra, fazendo as três mulheres se sentem apreensivas, pois ele não é capaz de verbalizar o que sente. Na verdade, o que Chris vivenciou nos campos de batalha, e muitas outras vítimas de trauma relatam algo semelhante, vem a ser uma "história impossível”, o que é definido pelo Caruth da seguinte forma: "The traumatized, we might say, carry an impossible history within them, or they become the symptom of a history that they cannot entirely possess." (CARUTH, 1995, p. v).

De fato, a saúde mental debilitada de Chris surge como um choque para as três mulheres de sua vida: sua esposa, Kitty, a quem ele não reconhece mais; a ex-amante de Chris, Margaret, que ainda o ama (e vice-versa), e sua prima, Jenny, que também nutre uma grande afeição por ele e ciúmes das outras duas mulheres. O drama vivido por essas três mulheres intensifica-se ainda mais após o psiquiatra, Dr. Anderson, intervir em favor de recuperar o caso de amnésia total de seu paciente e conduzir um interrogatório que mais se assemelha a um julgamento, em tons bastante kafkianos, sobre a vida pré-guerra de Chris Baldry. Suas confissões geram hostilidade mas, ao invés de dividir o grupo de mulheres, elas promovem reflexões sobre a fragilidade e a vulnerabilidade dos homens em tempos de guerra. Sugere-se, também, que essas mulheres, outrora sustentadas financeiramente por Chris, teriam de encontrar uma fonte de renda capaz de manter a casa, elas mesmas e, possivelmente, Chris, dado o seu estado de saúde. Jenny revela a discrepância entre o que as mulheres do início do século XX esperavam de um soldado, em termos de comportamento social, e o que ela realmente testemunha, com base no sofrimento de seu primo. Primeiramente, ela compara os pesadelos envolvendo seu primo no campo de batalha com a visão da guerra que ela aprendera ao assistir filmes de guerra, conforme segue:

Of late I had had bad dreams about him. By nights I saw Chris running across the brown rottenness of No-Man's-Land, starting back here because he trod upon a hand, not even looking there because of the awfulness of an unburied head, and not till my dream was packed full of horror did I see him pitch forward on his knees as he reached safety, if it was that. For on the war- films I have seen men slip down as softly from the trench-parapet, and none but the grimmer philosophers could say that they had reached safety by their fall. (WEST, 2004, p. 6). 
A referência fílmica, aludida na passagem acima, é comentada por Santanu Das conforme segue:

The Battle of the Somme (1916), watched by some 80 per cent of the adult population in Britain, introduced many of its audiences at once to cinema and war: it brought home the scale of the war's devastation through images of bombed landscapes, ruined buildings and killed and wounded men. (DAS, 2006, p. 230).

Seja para o que se concebia à época como "educação", seja para a propaganda de guerra, é certo que as autoridades britânicas usavam filmes para construir a visão do público da Primeira Guerra. Por mais que a narradora pareça impressionada com a nitidez dessas cenas do filme, ela se depara com uma sensação ainda pior quando ela acorda de seus pesadelos, o que faz com que ela coloque em xeque seus pontos de vista sobre a guerra. Ela parece ressoar as vozes de outras mulheres da sua geração, ao ponderar que:

And when I escaped into wakefulness it was only to lie stiff and think of stories I had heard in the boyish voice of the modern subaltern, which rings indomitable, yet has most of its gay notes flattened: "We were all of us in a barn one night, and a shell came along. My pal sang out, 'Help me, old man; I've got no legs!' and I had to answer, 'I can't, old man; I've got no hands!' Well, such are the dreams of Englishwomen to- day. (WEST, 2004, p. 6).

O que parece ser, à primeira vista, uma descrição irônica revela-se como um pesadelo de mutilação. Os "sonhos de mulheres inglesas" estão relacionados, na verdade, ao despertar das mulheres para a face mais trágica de guerra - o que significa que os seus homens não necessariamente retornariam da guerra como heróis, se é que eles retornariam aos seus lares.

Em termos simbólicos, é possível pensar que a casa onde as três mulheres vivem com Chris representa uma espécie de "laboratório"; um locus de onde elas observam a guerra e formulam seus pontos de vista a respeito desse conflito. Na trama psicológica complexa que se desenvolve entre as mulheres que vivem com Chris sob o mesmo teto, a guerra é mostrada a partir de um "front interno". Também pode-se dizer que as três mulheres atuam como ouvintes e, ao fazê-lo, eles podem oferecer uma ajuda considerável no sentido de ajudar Chris a elaborar suas vivências traumáticas durante a guerra, que culminaram em um estado de amnésia traumática.

Muitos teóricos do trauma ressaltam a importância de haver uma comunidade de ouvintes. Anne Whitehead afirma que: "The multiplicity of testimonial voices suggests that recovery is based on a community of witnesses. Through the compassionate sharing of the story, trauma resolves itself into new forms and constellations." (WHITEHEAD, 2004, p. 88). Isso se torna possível uma vez que os ouvintes compassivos, cuja atitude é o reverso da violência que o evento traumático infligiu, auxiliam as vítimas de trauma ao manifestarem a vontade de ouvi-las. Outra teórica do trauma, Leigh Gilmore, pondera que: "Trauma lacks 
an other who will return the story without violence to the speaker by listening to it carefully." (GILMORE, 2001, p. 31).

As três mulheres, apesar de sua perplexidade em relação à condição traumática de Chris, mostram grande empatia por seu estado mental debilitado. Kitty, de maneira semelhante à Penélope de Homero, não abandona a propriedade, construída com o trabalho duro de seu marido, após ele partir para a guerra. Independentemente das disputas que se travam na casa, as três mulheres têm em comum o amor para com Chris mas, por ser a dona da casa, Kitty é aquela que exerce maior poder nesse espaço, cujo nome sugere tratar-se de uma propriedade inglesa abastada (Baldry's Court). Ao invés de procrastinar pretendentes, Kitty lida com a prima do marido e sua amante, exercendo domínio sobre ambas.

Outra analogia mítica pode ser feita em relação a Margaret, ex-amante de Chris e a única lembrança que sua amnésia traumática não havia excluído. A maneira através da qual ela o resgata de seu pesadelo pode ser comparada ao gesto de uma Valkyria, que salva um guerreiro em uma tentativa desesperada de retirá-lo do campo de batalha e levá-lo para uma versão mais próxima do Walhalla. A narradora descreve:

How her near presence had been known by Chris I do not understand, but there he was, running across the lawn as night after night I had seen him in my dreams running across No-Man's- Land. I knew that so he would close his eyes as he ran; I knew that so he would pitch on his knees when he reached safety. I assumed naturally that at Margaret's feet lay safety even before I saw her arms brace him under the armpits with a gesture that was not passionate, but rather the movement of one carrying a wounded man from under fire. (WEST, 2004, p. 52).

Em seu texto introdutório à edição de The Return of the Soldier pela Random House (2004), Verlyn Klinkenborg recorda um fato interessante sobre o romance de Rebecca West: "In October 1917, when she learned that The Return of the Soldier - her first novel - had been accepted for publication, Anthony [her son with Wells] was already three, incendiary bombs and aerial torpedoes were falling all around her, and West had been reading Tolstoy." (KLINKENBORG, 2004, p. xvi).

O romance foi escrito por Rebecca West durante os bombardeios da Primeira Guerra, cerca de um ano após a Batalha do Somme. O interesse da escritora por essa batalha também é aludido no romance através do filme homônimo que ela assiste. O romance de Tolstoi, em analogia com a guerra, era, muito provavelmente, a coleção Guerra e Paz (1865-1869).

A narrativa de Rebecca West, tal qual a de Tolstoi, se dá in medias res. A história começa com Jenny relembrando o dia em que seu primo embarcou rumo à França e a recordação, numa certa manhã, de tudo que o primo havia feito no ano anterior, antes de ele ingressar ao front. Frank Baldry, primo de Chris, escreveu uma carta para Jenny relatando seu encontro com o já amnésico Chris em um hospital em Boulogne, referindo-se à cidade de Boulogne-sur-Mer, no norte da França, onde a Batalha do Somme ocorreu. O ano em que eles se encontram coincide com a ofensiva do Somme, no caso, 1916. A maioria das narrativas de ficção de trauma parecem ter em comum a característica de quebrar a cronologia narrativa e, mais especificamente, de serem reiterativas. Isso se dá, possivelmente, visto 
que tais relatos, assim como o trauma propriamente dito, baseiam-se na repetição ${ }^{2}$. Anne Whitehead explica que: "One of the key literary strategies in trauma fiction is the device of repetition, which can act at the levels of language, imagery or plot. Repetition mimics the effects of trauma, for it suggests the insistent return of the event and the disruption of narrative chronology or progression." (WHITEHEAD, 2004, p. 86).

O romance de Rebecca West demonstra compartilhar uma característica importante com Guerra e Paz: suas histórias se definem após o começo da guerra, sendo que nenhuma informação anterior, ou de fundo histórico, sobre as guerras a que se referem, é fornecida ao leitor. Segundo Ginzburg, o cenário in medias res confere um valor único à representação ficcional da história. Ele fala especificamente sobre Guerra e Paz, de Tolstoi, mas a afirmação também é válida em relação ao romance de Rebecca West:

Em Guerra e paz... tudo o que precede o ato da narração (das recordações pessoais à memorialística da era napoleônica) é assimilado e deixado para trás a fim de permitir que o leitor entre numa relação de especial intimidade com os personagens, de participação imediata nas suas histórias. Tolstoy supera de um salto a brecha inevitável entre as pistas fragmentárias e distorcidas de um acontecimento (uma batalha, por exemplo) e o próprio acontecimento. (GINZBURG, 2006, p. 271).

É importante observar que o relato ficcional de Tolstoi das guerras napoleônicas, mais notavelmente da batalha de Austerlitz, bem como a retirada final das tropas francesas derrotadas tanto pelo exército quanto pelo frio da Rússia - é recontada por mais de cem personagens reais e fictícios. O intervalo de tempo entre 1805 e 1820 , quando as forças russas, lideradas pelo Czar Alexander I, lutaram contra o exército de Napoleão, não é replicado mas, outrossim, reconstruído através da imaginação.

As matérias-primas para o romance histórico de Tolstoi - o expansionismo, a ditadura e a aristocracia da Rússia no início do século XIX - são repletas de digressões teóricas. Em The Return of the Soldier, o leitor pode avaliar batalhas históricas (a saber, a Batalha do Somme) através de uma multiplicidade de vozes. No caso da narrativa de guerra de Rebecca West, o leitor tem acesso às vozes de três mulheres que habitam a mesma casa, o que investe o romance de um jogo polifônico bastante interessante. Sendo que Jenny, a prima e não por acaso a narradora, parece representar de forma mais evidente a consciência e a voz das mulheres sobre as guerras.

Se é verdade que as ficções de guerra apresentam algum tipo de vantagem peculiar em relação aos relatos históricos tradicionais, isso se deve, possivelmente, aos fragmentos da memória cultural que podem ser acessados nas vozes de personagens fictícios. Ginzburg vê nessas narrativas do próprio conteúdo da micro-história, conforme ele explica a seguir:

$2 \mathrm{O}$ aspecto reiterativo das narrativas de trauma foi trabalhado com maior densidade em minha tese de doutorado, intitulada "Nas tramas do trauma: as mulheres, a guerra e a escrita feminina em literaturas de língua portuguesa" (2016), defendida na Pontifícia Universidade Católica de Minas Gerais. 
Mas esse salto, essa relação direta com a realidade, só pode se dar (ainda que não necessariamente) no terreno da ficção: ao historiador, que só dispõe de rastros, de documentos, a ele é por definição vedado. Os afrescos historiográficos que procuram comunicar ao leitor, com expedientes muitas vezes medíocres, a ilusão de uma realidade extinta, removem tacitamente esse limite construtivo do ofício do historiador. A micro-história escolhe o caminho oposto: aceita o limite explorando as suas implicações gnosiológicas e transformando-as num elemento narrativo. (GINZBURG, 2006, p. 271).

Uma parte da memória histórica que não havia sido o foco principal da análise histórica tradicional - a opinião das mulheres sobre a guerra - é cuidadosamente resgatada, e ficcionalmente reconstruída, pelo romance de Rebecca West e, sob a perspectiva micro-histórica, contribui para uma compreensão mais ampla da Primeira Guerra. As maneiras como as mulheres foram afetadas pelo "monstro de guerra" é, concomitantemente com a percepção da susceptibilidade dos homens, um indicador de como as mulheres atuaram na história da Primeira Guerra enquanto protagonistas. O mesmo se dá com as personagens de The Return of the Soldier. No romance, chama atenção o título do "soldado que retorna", supostamente o protagonista, em benefício das três personagens femininas: seu caso de amor com Margaret seria prejudicado pela compaixão "maternal” da ex-amante por sua condição e Chris não parece ter elaborado suas vivências traumáticas na guerra, o que sugere um não-retorno da personagem à vida normal ou, ainda, uma incapacidade de cumprir sua suposta tarefa "heroica". Ele vagueia ao redor da casa e olha para ela e seus habitantes com indiferença e, ao final da narrativa, ele continua a se sentir como um soldado perdido. Ao retirar o foco de Chris e enfocar as personagens femininas, a atenção dos leitores é imediatamente deslocada para as três mulheres, bem como para suas opiniões e visões sobre a guerra, o que lhes eleva à condição de protagonistas do enredo.

A Primeira Guerra e sua influência sobre as mulheres são descritas por uma autora que testemunhou e escreveu sobre os marcos históricos do século XX (Rebecca West nasceu em 1892 e morreu em 1983), o que confere à narrativa de West uma maior credibilidade. Hobsbawm, que nasceu durante a Primeira Guerra, em 1917, salienta que "For anyone of my age-group who has lived through all or most of the Short Twentieth Century this [to understand and explain the First and the Second World Wars] is inevitably an autobiographical endeavour." (HOBSBAWM, 1996, p. iii).

As lembranças dos eventos mais importantes do século $\mathrm{XX}$, fornecida tanto por homens quanto por mulheres, na visão de Hobsbawm, parecem definir os papéis que tanto eles quanto elas desempenharam na história, assim como suas próprias histórias. Ele afirma que:

We are talking about, amplifying (and correcting) our own memories. And we are talking as men and women of a particular time and place, involved, in various ways, in its history as actors in its dramas ... as observers of our times and, not least, as people whose views of the century have been formed by what we have come to see as its crucial events. We are part of this century. It is part of us. (HOBSBAWM, 1996, p. iii). 
O trauma da guerra afetou a vida de Chris e não seria diferente com as três mulheres de sua vida. Pode-se pensar que o trauma da guerra tornou-se parte da vida dessas mulheres. A narrativa de Rebecca West convida o leitor a aprender mais sobre os papeis desempenhados pelas mulheres durante a guerra, escrito por uma mulher cuja vida e obra notáveis marcaram praticamente um século inteiro.

\section{REFERÊNCIAS BIBLIOGRÁFICAS}

ABREU, Denise Borille de. "Nas tramas do trauma: as mulheres, a guerra e a escrita feminina em literaturas de língua portuguesa". Tese de Doutorado. Belo Horizonte: Pontifícia Universidade Católica de Minas Gerais, 2016.

CARUTH, Cathy. Trauma: Explorations in Memory. Baltimore: The Johns Hopkins University Press, 1995.

DAS, Santanu. Touch and Intimacy in First World War Literature. Cambridge: Cambridge Univeristy Press, 2006.

GILMORE, Leigh. The Limits of Autobiography: Trauma and Testimony. Ithaca: Cornell University Press, 2001.

GINZBURG, Carlo. "Micro-história: duas ou três coisas que sei a respeito". O fio e os rastros: verdadeiro, falso, fictício. São Paulo: Companhia das Letras, 2006, pp. 249-279.

HIGONNET, Margaret R. Lines of Fire: Women War Writers of World War I. New York: Plume, 1999.

HOBSBAWM, Eric. The Age of Extremes:1914-1991. New York: Vintage Books, 1996.

HYNES, Samuel. A War Imagined: The First World War and English Culture. New York: Atheneum, 1991.

KLINKENBORG, Verlyn. Introdução. The Return of the Soldier. By Rebecca West. New York: Random House, 2004, pp. xv-xxi.

WEST, Rebecca. The Return of the Soldier. New York: Random House, 2004.

WHITEHEAD, Anne. Trauma Fiction. Edinburgh: The Edinburgh University Press, 2004. 